\title{
The Trinity Triangle and the Homonymy of the Word "Is" in Natural Language
}

\author{
A Logically Consistent Discrete Mathematical Representation of the \\ Trinity by Means of Algebra of Morality and Formal Ethics \\ Vladimir Lobovikov \\ Ural Branch of the Academy of Sciences
}

\begin{abstract}
There are philosophers and logicians who do think that the Trinity-triangle makes up an evident formal-logic inconsistency demonstrating convincingly that Christian faith is illogical and hence irrational one. The present paper submits a systematic counter-argumentation against such thinking. According to the submitted counter-arguments, there is no formal-logic inconsistency in the Holy-Trinity-triangle: There is only a logic-linguistic illusion of such inconsistency which illusion is naturally produced by the ambiguity of the word "is" in natural language. The author has invented an effective remedy for that illusion, namely, a precise formulation of the generalized and thus modernized Guillotine of Hume by means of an artificial language of two-valued algebraic system of formal ethics of moral rigor. Systematical using the mathematized formulation of the generalized Hume's Guillotine cuts down the mentioned linguistic illusion of logical inconsistency. Thus, the paper essentially interconnects discrete mathematical representations of formal logic of thinking and formal ethics of acting. In relation to contemporary symbolic logic, the author submits not a technical result solving some important particular problem concerning some specific system of symbolic logic but a significantly new result of conceptual work concerning logic in general and its interconnection with mathematical ethics. The old idea of logic as a moral science is transformed into a novel idea of symbolic logic as a brunch of mathematical ethics. In particular, two-valued algebra of classical formal logic is considered as a particular case of two-valued algebra of formal ethics of moral rigor. The submitted conception of logic is instantiated by applying it to the knotty logic-problem of Holy-Trinity-triangle.
\end{abstract}

Keywords: symbolic-logic, mathematical-ethics, mathematical-theology, the-Holy-Trinity, algebra-of-formal-ethics, moral-evaluation-function, formal-ethical-equivalence, formal-ethical-entailment

\section{The Holy Trinity Triangle}

One can find quite representative examples of formulating the doctrine of Trinity in writings of St. Augustine $(1963 ; 1994)$ and St. Thomas Aquinas (1994a; 1994b). Let us begin this paper with citing St. Augustine:

The Trinity, one God, of Whom are all things, through Whom are all things, in Whom are all things. Thus the Farther and

Vladimir Lobovikov, Dr. Hab., full prof., principal researcher, Institute of Philosophy and Law, Ural Branch of Russian Academy of Sciences, Russia; main research fields: Inventing and Investigating Discrete Mathematical Models in the Humanities-Logic, Ethics, Aesthetics, Metaphysics, Philosophy of Language, Philosophy of Science, Philosophy of Law, Political Economy, and Philosophy of Religion. Email: vlobovikov@mail.ru. 
the Son and the Holy Spirit, and each of these by Himself, is God, and at the same time they are all one God; and each of them by Himself is a complete substance, and yet they are all one substance. The Farther is not the Son nor the Holy Spirit; the Son is not the Farther nor the Holy Spirit; the Holy Spirit is not the Farther nor the Son: but the Farther is only Farther, the Son is only Son, and the Holy Spirit is only Holy Spirit. To all three belong the same eternity, the same unchangeableness, the same majesty, the same power. (Augustine 1994, 705-6)

The 1st World Congress "Logic and Religion" (April 01-05, 2015, João Pessoa, Brazil) has demonstrated that the old problem of logic consistency of Christian theology remains quite actual even today. Various aspects of this problem were discussed in papers of Bertato (2015), Bertato and Toniolo (2015), Béziau and Costa (2015), Lobovikov (2015), Rocha (2015), Trepczyński (2015), and others. The below paper is a complete representation of my talk at the mentioned congress on logic and religion. At the very beginning of this interdisciplinary paper somewhat surprisingly combining contemporary formal logic, formal ethics and discrete mathematics with religious studies and theology, it is relevant to emphasize that this combining is not arbitrary one: It necessarily represents a fundamental unity of logic, ethics, and theology.

Since XIX century, formal logic uses mathematics (especially algebra) and in this specific sense the contemporary symbolic formal logic may be called mathematical one. Since XX century, formal ethics uses mathematics (especially algebra) too (Lobovikov 1984; 1999), hence in this specific sense, the contemporary symbolic formal ethics may be called mathematical ethics respectively. A system of results of applying mathematical logic and mathematical ethics to religious studies and theology for dissolving difficult theological problems may be called mathematical theology. Obviously, the meaning of the term "mathematical theology" is somewhat unusual and conventional. Nevertheless it is not only convenient but also quite relevant to use the name "mathematical theology" in respect to the mathematical-logical-theological investigations related to K. Gödel's formal proof of God's existence or in respect to the mathematical studies of relationship between God and infinity (Gödel 1995; Anderson 1990; Bjørdal 2015; Fitting 2002; Fuhrmann 2005; Oppy 1995; Plantinga 1965; Sobel 1987; Weingartner 2015; Steinhart 2009; Voss 2003). According to investigations presented by Fuhrmann (2015), the overwhelming majority of laymen estimate Gödel's formal proof of God's existence as something quite exotic and not important but people know that such a proof does exist. In contrast to the quite exotic but well-known applications of mathematical logic to theology, the question of relevance of using the term "mathematical theology" in respect to the above-mentioned applications of mathematical ethics to theological problems is open until colleagues have an exemplification of applying mathematical ethics to theology. Therefore, in this paper I intend to undertake attempts to construct a concrete example of such applying.

Hereafter I continue discussing the Holy-Trinity-triangle investigated in (Schang 2014). I submit another interpretation of the triangle. In my interpretation, the one contains not a logic inconsistency but an illusion of it as the word "is" is used in two different meanings. In all the three "IS-NOT"s (included in the below Figure 1), the word "IS" stands for the well-known logic connective. But in all the rest three cases the word "IS" stands for the "formal-ethical-(axiological)-equivalence-relation" defined precisely in two-valued algebra of formal ethics (Lobovikov 1999; 2009b; 2014a; 2015). The mentioned formal-ethical-equivalence and the formal-logical one are logically different relations of equivalence although in natural language they are represented by one and the same word-homonym "is." Hence, in the below picture, they do not make up a logic contradiction. Below "The Father," "The Son," "The Holy Spirit," "God" are precisely defined as moral-evaluation-functions. In two-valued algebra of formal ethics by means of the definitions, it is easy to 
figure out the formal-ethical equations demonstrating the Unity of the Trinity. The inconsistency illusion in question is eliminated by virtue of "Hume's Guillotine" generalized and precisely formulated within the algebraic system of formal ethics (Lobovikov 2014a; 2014b). Another option of eliminating the illusion of inconsistency of Christian theology is submitted in (Trepczyńsk 2015). Trepczynski perfectly recognizes and convincingly demonstrates that applying the classical first-order predicate logic to the Trinity-triangle and to the case of Christ's-two-natures generates logic contradictions (Trepczyński 2015, 122). Therefore, to avoid them Trepczyński $(2015,123)$ suggests an interesting idea of local (non-standard) logic in Christian theology. I think that Trepczynski's idea is worth developing further but in this paper I submit and elaborate another (supplementary) option of excluding the illusion of logic inconsistency of Christian theology.

Nowadays, it is a firmly established and well-recognized fact that formulating the doctrine of Unity of the Trinity at the level of ambiguous natural language does not exclude a possibility of generating logic contradictions. It is easy to see this by virtue of the below triangle which is a graphic model of the above citation from (Augustine 1994, 705-6).

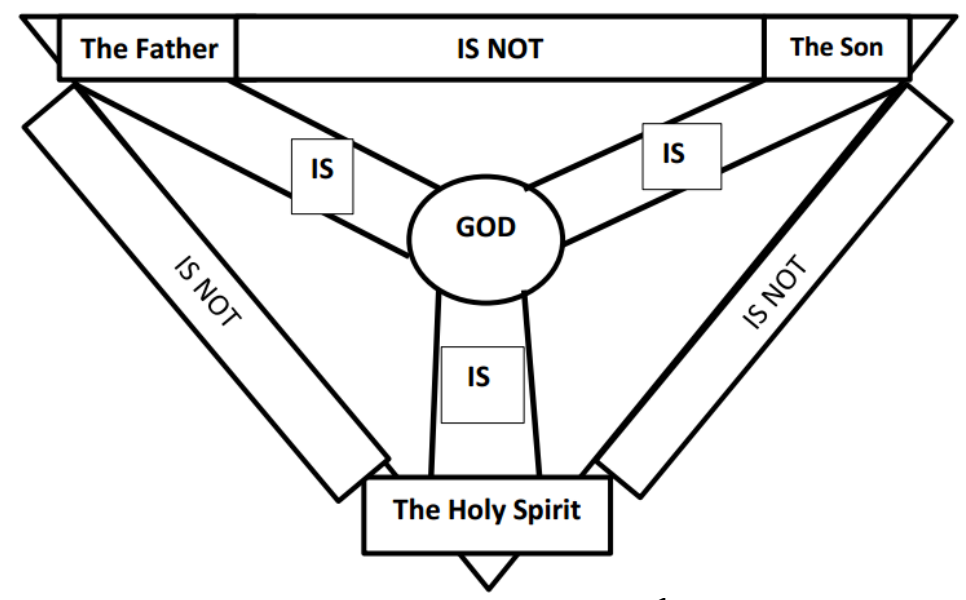

Fig. 1. The Trinity triangle ${ }^{1}$.

In contemporary special literature devoted to inventing and elaborating various options of resolving the Holy-Trinity-inconsistency-problem, there is a trend to utilize mereology (Rocha 2015). From some point of view, this trend appears quite naturally; its grounds and reasons are clear and seem relevant to the case. However, I have an opposite attitude to this option. According to classical theology God Is Simple, "He is not compound." A respectable demonstration of the religious tenet of the simplicity of God can be found, for instance, in "The Summa Theologica" (Aquinas 1994a, 14-20). God cannot consist of proper parts as "He is indivisible One." Consequently no proper parts (of God) make up God (as a whole). Therefore, being a general theory of parts (and part-whole relations), mereology is not relevant to the case. Then what abstract formal apparatus could be relevant to the case under investigation? In this paper, I submit and study a hypothesis that the role of abstract formal apparatus effectively applicable to the problem under consideration could be performed by a discrete mathematical model (algebraic system) of metaphysics understood as formal axiology, in particular, as two-valued algebra of formal ethics of moral rigor.

\section{Algebra of Morality and Formal Ethics}

Below the possibility of mathematical representation of moral activity is demonstrated by the elementary 
mathematical ethics of moral rigor-two-valued algebra of good and evil (Lobovikov 1999; 2007; 2009a; 2010a; 2011; 2014a; 2014b). This algebra is based upon the set of moral acts and agents. By definition, moral acts are such and only such operations, which are either good, or bad ones in the moral meaning of the words "good" and "bad." Algebraic operations defined on the set of moral acts and agents are moral-evaluation functions (or moral-value ones). Moral-evaluation-variables of these functions take their values from the set $\{\mathrm{g}$, b). Here the symbols "g" and "b" stand for the moral values "good" and "bad," respectively. The functions take their values from the same set. The symbols: " $x$ " and " $y$ " stand for moral-forms of acts. Elementary moral-act-forms deprived of their contents are independent moral-evaluation-variables. Compound moral-act-forms deprived of their contents are moral-evaluation-functions determined by these variables.

Let symbol $\Sigma$ stand for the moral evaluator, i.e., that person (individual or collective one-it does not matter), in relation to which all evaluations are generated. In the moral-evaluation-relativity theory, $\Sigma$ is a variable: Changing values of the variable $\Sigma$ can result in changing moral evaluations of concrete acts and agents. However, if a value of the variable $\Sigma$ is fixed, then moral evaluations of concrete acts and agents are definite.

Speaking of moral-value functions in this paper, I mean the following mappings (in the proper mathematical meaning of the word "mapping"): $\{\mathrm{g}, \mathrm{b}\} \rightarrow\{\mathrm{g}, \mathrm{b}\}$, if one speaks of the moral-value functions determined by one moral-value variable; $\{\mathrm{g}, \mathrm{b}\} \times\{\mathrm{g}, \mathrm{b}\} \rightarrow\{\mathrm{g}, \mathrm{b}\}$, where " $\times$ " stands for the Cartesian multiplication of sets; if one speaks of the moral-value functions determined by two moral-value variables; $\{\mathrm{g}, \mathrm{b}\}^{\mathrm{N}} \rightarrow\{\mathrm{g}, \mathrm{b}\}$; if one speaks of the moral-value functions determined by $\mathrm{N}$ moral-value variables, where $\mathrm{N}$ is a finite positive integer.

In a hitherto not recognized clearly and hence not-studied systematically formal-axiological semantics of natural language, words, small word-combinations, and even long expressions stand for some moral-value functions or for some complicated compositions of the functions. Below I submit an example of mathematically elementary moral-value-functions determined by one moral-value variable.

The glossary for the below-submitted moral-value-table 1: Let the symbol $B x$ stand for the moral-value function "being (existence), life of (what, whom) $x . " N x$ stands for the moral-value function "non-being (nonexistence), death of (what, whom) $x$." $U x$ stands for "source, cause, producer, parent of (what, whom) $x$." $F x$ stands for the moral-value function "father of (what, whom) $x$. " $O x$ means the moral-value function "outcome, product, fruit of (what, whom) $x$." $S x$ means the moral-value function "son of (what, whom) $x$." $J x$ means the moral-value function "spirit of (what, whom) $x . " T x$ means the moral-value function "thing (what, who) $x$." $Z x$ means the moral-value function "self-destruction, self-extermination, suicide of (what, whom) $x$." $P x$ means the moral-value function "self-preservation, self-conservation, self-protection, self-defense of (what, whom) $x$." The introduced functions are precisely defined by the following Table 1.

Table 1

The Functions Determined by One Variable

\begin{tabular}{|l|l|l|l|l|l|l|l|l|l|l|l|}
\hline$x$ & $B x$ & $N x$ & $U x$ & $F x$ & $O x$ & $S x$ & $J x$ & $T x$ & $Z x$ & $P x$ \\
\hline $\mathrm{g}$ & $\mathrm{g}$ & $\mathrm{b}$ & $\mathrm{g}$ & $\mathrm{g}$ & $\mathrm{g}$ & $\mathrm{g}$ & $\mathrm{g}$ & $\mathrm{g}$ & $\mathrm{b}$ & $\mathrm{g}$ \\
\hline $\mathrm{b}$ & $\mathrm{b}$ & $\mathrm{g}$ & $\mathrm{b}$ & $\mathrm{b}$ & $\mathrm{b}$ & $\mathrm{b}$ & $\mathrm{b}$ & $\mathrm{b}$ & $\mathrm{b}$ & $\mathrm{g}$ \\
\hline
\end{tabular}

\section{A Hitherto Unknown Mathematical Theology: God, Truth, and Good; the Unity of Mathematical Theology, Symbolic Logic, and Mathematical Ethics, Respectively}

Theology is systematical studying God. According to the here-submitted definition, one of important options of developing mathematical theology is systematical studying formal-axiological meanings of 
(somewhat different) God's names and everything immediately relevant to them (Janowitz 1991; Pseudo-Dionisius 1980) as moral-value functions (in the above-defined mathematical meaning of the term). Below I submit a set of examples of such moral-value-functions (elementary ones from purely mathematical viewpoint) determined by one moral-value variable which are fundamental for any theology.

The glossary for the below-submitted moral-value-table 2: Let the symbol $G x$ stands for the moral-value function "God of (what, whom) $x$ in monotheistic world religion." Ix stands for the moral-value-function "god of (what, whom) $x$ in polytheistic local (barbaric) religion." $D x$ means the moral-value-function "daemon of $x$ in polytheistic local religion." $A x$ means "Anti-God (God's Enemy) of (what, whom) $x$ in monotheistic world religion." These moral-value functions are precisely defined by the following Table 2.

Table 2

On God

\begin{tabular}{lllll}
\hline$x$ & $G x$ & $I x$ & $D x$ & $A x$ \\
\hline $\mathrm{g}$ & $\mathrm{g}$ & $\mathrm{g}$ & $\mathrm{b}$ & $\mathrm{b}$ \\
$\mathrm{b}$ & $\mathrm{g}$ & $\mathrm{b}$ & $\mathrm{g}$ & $\mathrm{b}$ \\
\hline
\end{tabular}

In the glossary for Table 2 in one sentence, the word "God" starts with the capital letter "G" but in another sentence the word "god" starts with the small letter "g." Here it is worth emphasizing that this is not a mistake by negligence: This is implemented on principle. The deliberately implemented difference indicates to the important difference of formal-axiological meanings of the word in monotheistic world religions and polytheistic local ones. It is easy to see the significant difference between the two formal-axiological meanings of the word, i.e., between the two moral-value-functions $G x$ and $I x$, by attentive comparing their tabular definitions (see Table 2).

According to Church Fathers, God is One, but He has many somewhat different names, for instance, "Being," "Reason," "Nature," "Law," "Power," "Beauty," "Truth," "Good" (Janowitz 1991; Pseudo-Dionisius 1980). However, in spite of some difference of meanings of the mentioned words, their moral-value-functional meanings are formally-axiologically equivalent. This formal-axiological equivalence models the Unity of God possessing many names. As "Truth" and "Good" are names of God (Pseudo-Dionisius 1980), there must be a fundamental formal-axiological linkage between logic dealing with truth and ethics dealing with good. In some sense, logic is an important part of theology as logic instructs humans how to think not leaving truth (of premises) for lie (of conclusions), i.e., how to think not leaving God for His enemy. The same can be said about the natural law and morals. They instruct living creatures how to behave not leaving good (actions) for evil (ones), i.e., how to behave not leaving God for His enemy. In the empirical world, facts and values are logically independent but in the world of value, logic and ethics are formally-axiologically equivalent. Moreover even in the empirical world, logic and ethics are significantly connected.

\section{Kukasiewicz Statement of Moral Essence of Logic}

It is well-known that according to famous Polish logician Jan Lukasiewicz: "Logic is morality of thought and speech" (Woleński 2014). Below let us consider systematically possible consequences of accepting this philosophical statement, at least, as a hypothesis. ${ }^{2}$ Ethics deals with morality of any human activity (speaking-and-thinking is a particular case of acting). Consequently, moral-form-of-activity (deprived of its specific contents) is a generalization of logic-form of thought-and-speech (deprived of its specific contents). 
Consequently, formal ethics is a generalization of formal logic. Hence, there is such a subsystem of system of formal ethics, which completely coincides with the classical two-valued system of formal logic. This basic subsystem of formal ethics is nothing but two-valued system of formal ethics of moral rigor of speaking-and-thinking. The two-valued formal ethics of moral rigor does exist although, evidently, it is neither realistic nor humanistic one. However, here it is important to recognize that the mentioned two-valued formal ethics of moral rigor is a much more universal doctrine than the classical logic. Let us consider the propositional classical logic as an example. Propositions are particular cases of moral actions. Truth-values (true and false) of propositions are particular cases of moral-values (good and bad) of actions, respectively. Hence, the classical two-valued algebraic system of formal logic is a particular case of two-valued algebraic system of formal ethics. Details (definitions, explanations, exemplifications, etc.) concerning this algebraic system of formal ethics can be found in Lobovikov's papers (2009b; 2010a; 2010b; 2014a; 2014b). Here I would like to consider only some interesting consequences of the hypothesis in question.

Definition 1 (of formal-ethical-equivalence-relation): in two-valued algebraic system of formal ethics, moral-evaluation-functions (moral-forms of human activity) $\Omega$ and $\Psi$ are formally-ethically equivalent (this is represented by the symbol " $\Psi=+=\Omega$ "), if and only if they acquire identical moral values (from the set $\{g$ $(\mathrm{good}), b(\mathrm{bad})\})$ under any possible combination of moral values of their moral-evaluation-variables.

Consequently, the relationship between notions "formal-logical-equivalence of logic-forms of thought-and-speech" and "formal-ethical-equivalence of moral-forms of human activity (any one)" can be represented by the following Figure 2 .

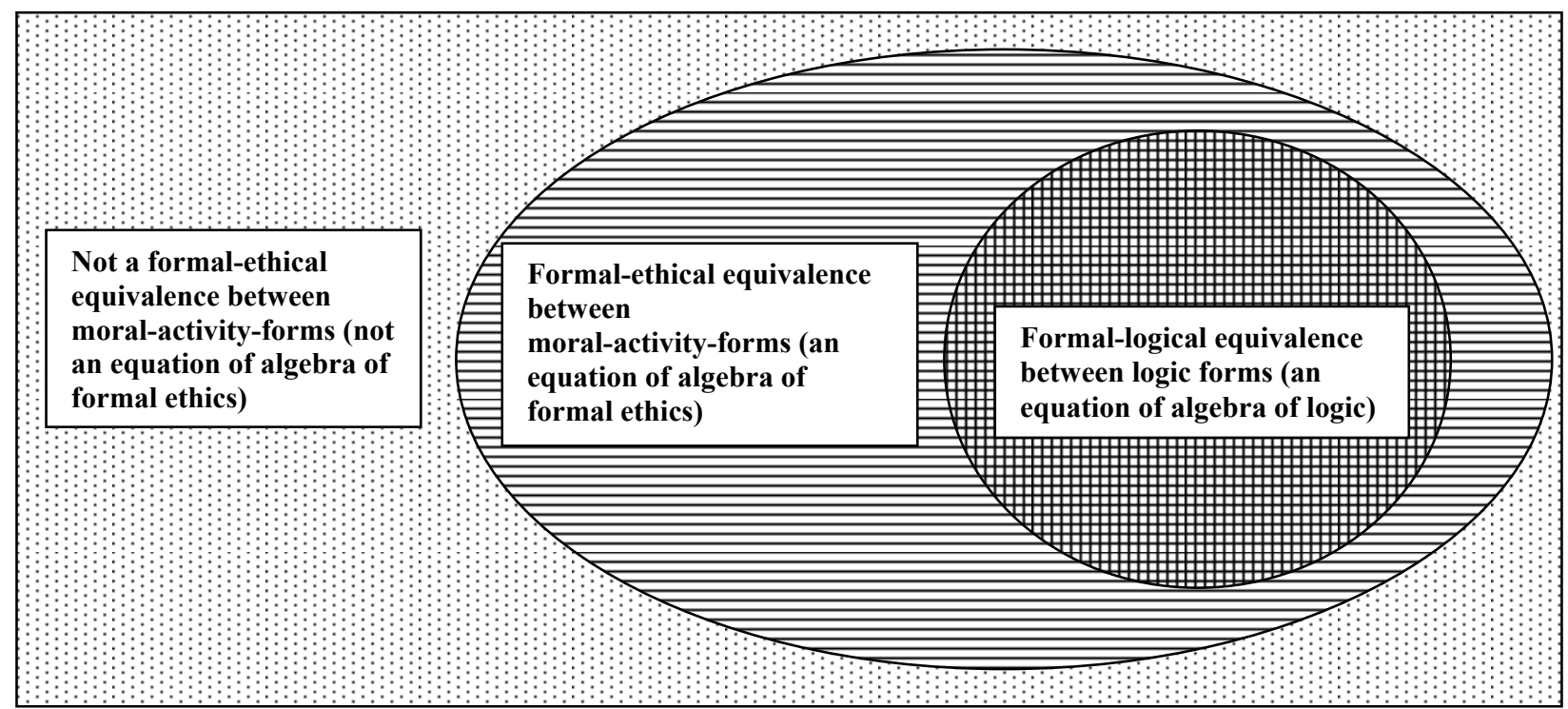

Fig. 2. Relationship between the two different formal equivalences.

In the natural language, the formal-ethical equivalence relation " $\mathrm{x}=+=\mathrm{y}$ " is represented by the ambiguous word-homonym "is." The ambiguity and homonymy of "is" was noticed and recognized by many prominent logicians and philosophers. For adequate understanding the present paper, here it is worthy of noting that "is" as the well-known logical connective and "is" as a linguistic means for representing the relation " $\mathrm{x}=+=\mathrm{y}$ " in the natural language, have significantly different meanings. Hence, substituting them for each other is strictly forbidden. Violating this prohibition produces linguistic illusions of logic contradictions with facts. Using the word "is" at 
the intersection between formal logic and formal ethics one must be careful.

Definition 2: in two-valued algebra of formal ethics, a moral-evaluation-function (moral activity form) is called formally-ethically (or invariantly) good one (or a law of algebra of formal ethics), if and only if it acquires the moral value $g$ (good) under any possible combination of moral values of its variables.

Consequently, the relationship between notions "formal-logical-law of thought-and-speech" and "formal-ethical-law of human activity in general" can be represented by the following Figure 3.

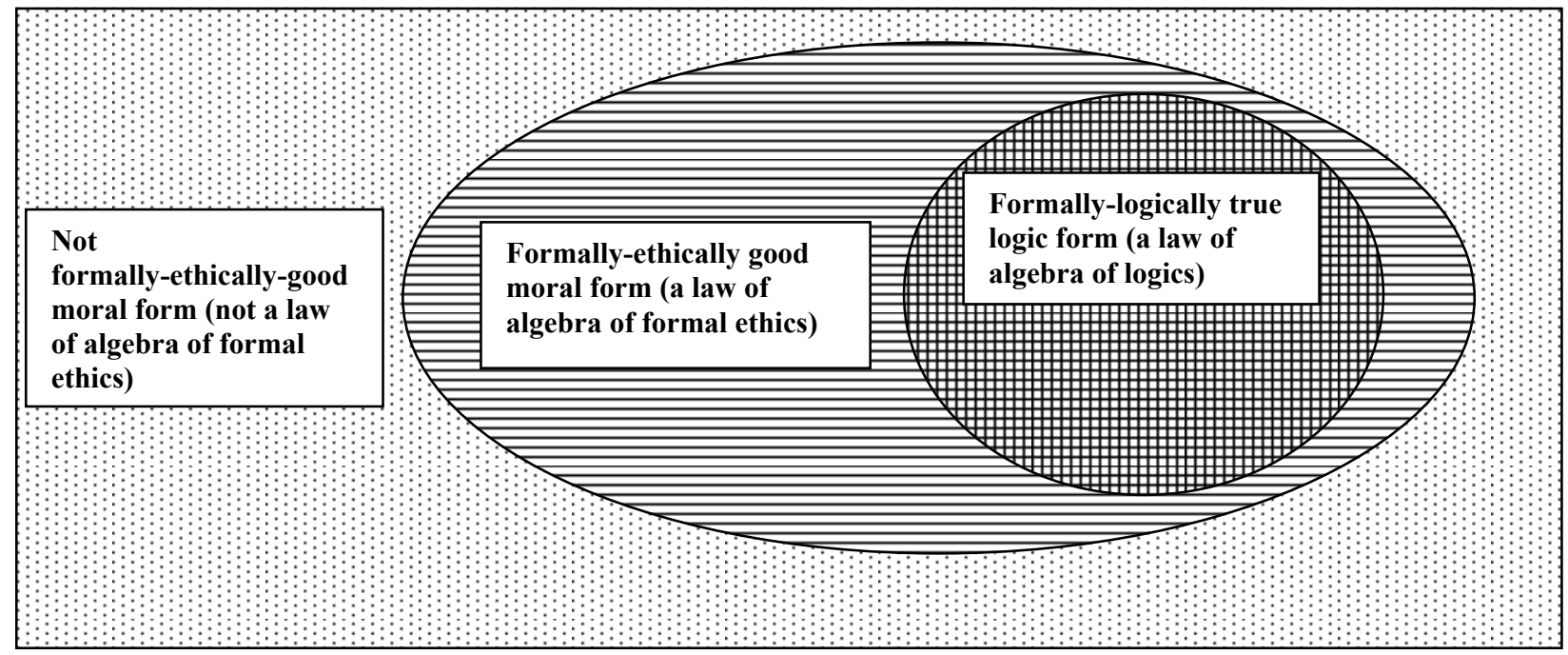

Fig. 3. Relationship between the two different notions of law (positive constant).

Definition 3 (of formal-ethical contradiction): in two-valued algebra of formal ethics, a moral-evaluation-function is called formally-ethically (or invariantly) bad one, if and only if it acquires the moral value $b(\mathrm{bad})$ under any possible combination of moral values of its variables.

Consequently, the relationship between formal-logical-inconsistency of thought-and-speech and formal-ethical-inconsistency of activity in general can be represented by the following Figure 4 .

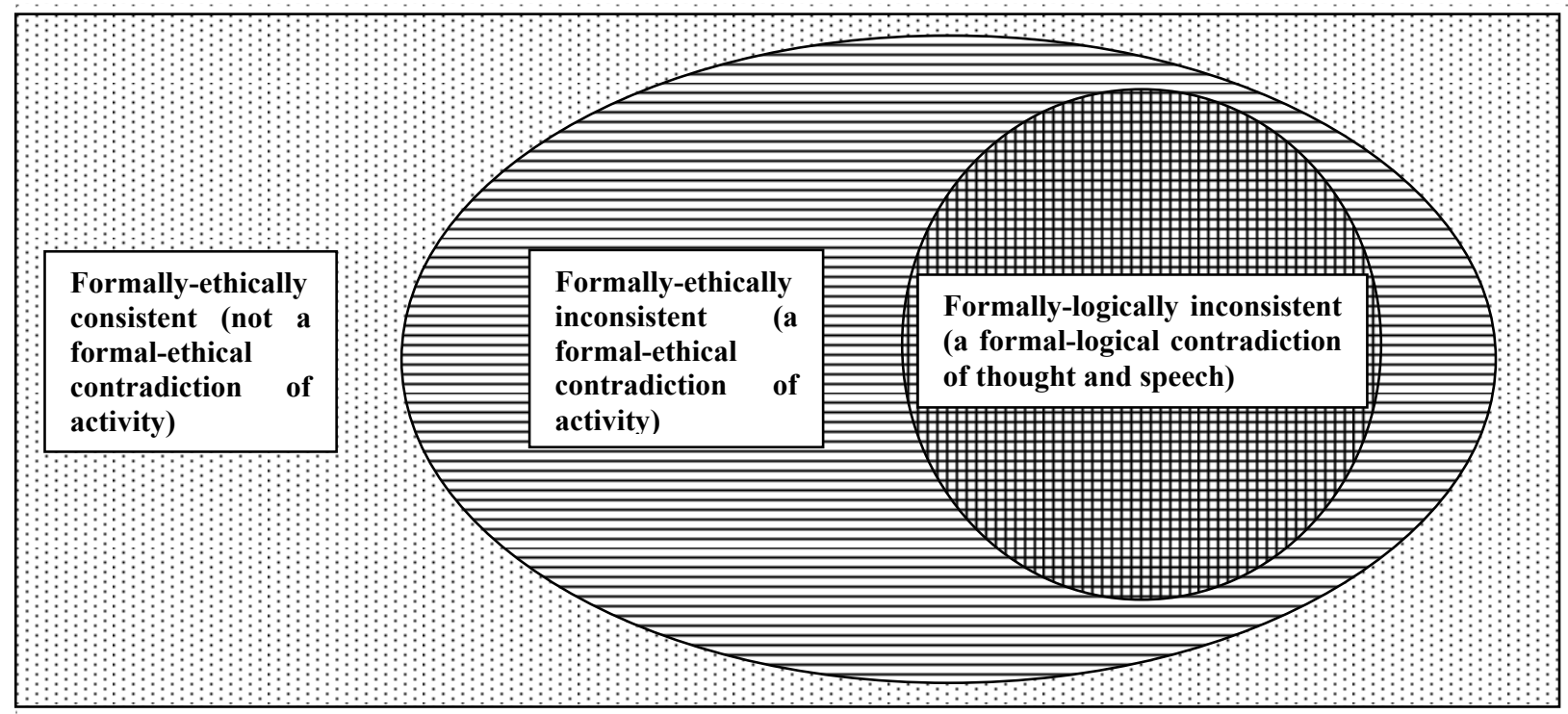

Fig. 4. Relationship between the two different notions of formal inconsistency (self-contradiction). 
Using the above-given definitions, one can demonstrate the following triples of formal-axiological equations.

The First Triple of Equations:

(1) $F G x=+=G x$ : The Father is God.

(2) $G x=+=S G x$ : God is The Son.

(3) $G x=+=J G x$ : God is The Holy Spirit (The Spirit of God).

The Second Triple of Equations:

(4) $F G x=+=S G x$ : The Father is The Son.

(5) $F G x=+=J G x$ : The Father is The Holy Spirit (The Spirit of God).

(6) $J G x=+=S G x$ : The Holy Spirit is The Son.

This outcome of mathematical modeling is surprising for those who are used to the opposition between logic and religion; hence, they could estimate (1)-(6) as paradoxes. However, there are only illusions of paradoxes caused by the ambiguity of the natural language of human creatures. For destroying such illusions of paradoxes in algebra of formal ethics, there is a principle of formal-logical autonomy of facts and accidental values, which is precisely formulated as follows.

\section{A Precise Formulation of Generalized Principle of Formal-Logical Independence (Separation) between Facts and Contingent (Relative) Values (Corresponding to Each Other)}

Let $\beta x$ stand for an act of informing (true or false affirming) that $x$ takes place in reality. Concerning the relationship between "=+=" and "logic equivalence," the principle in question may be formulated as the following rule (A\&B):

(A) From the truth of $x=+=y$, it does not follow logically that logic equivalence of $\beta x$ and $\beta y$ is true;

(B) From the truth of logic equivalence of $\beta x$ and $\beta y$, it does not follow logically that $x=+=y$ is true.

The illusion of paradox concerning equations (1)-(6) is destroyed by (A\&B). This illusion is a result of not-recognized "jumps" from formal-ethical equivalences of empirical (contingent) evaluations which are relative ones to formal-logical equivalences of facts (and back from the formal-logical equivalences of facts to the formal-ethical equivalences of empirical evaluations). In algebra of formal ethics such bridging the gap between facts and contingent (relative) values is strictly forbidden by (A\&B), which is an explication of important particular case of the general principle of mutual formal-logic autonomy of corresponding facts and contingent values (propositions and empirical evaluations). The rule (A\&B) can be universalized in the following way. Let us call this generalization (Y\&Z):

(Y) From $x=+=y$, it does not logically follow that $\beta x @ \beta y$;

(Z) From $\beta x @ \beta y$, it does not logically follow that $x=+=y$.

Here the symbol "๑)" stands for any element of the set of all binary formal logic operations.

As to the unary operations of algebra of formal ethics, the general fact-\&-contingent-value-autonomy principle can be precisely formulated as the following rule (U\&Q):

(U) From $\beta @ x$, it does not logically follow that $\beta x$;

(Q) From $\beta x$, it does not logically follow that $\beta @ x$.

Here the symbol “@” stands for any element of the set of all unary operations of algebra of formal ethics. This formulation of the principle of logic independence between facts and accidental values (corresponding to 
each other) can be found in Lobovikov's papers (2009b; 2010b; 2014a; 2014b).

The above-given precise formulation of the general principle of mutual formal-logic independence (separation) of corresponding facts and accidental values (fact-fixing-propositions and empirical evaluations) is extremely abstract and therefore here it is psychologically necessary to show an example of applying this abstract separation principle to a concrete situation. Let $\left(\mathrm{t}<+20^{\circ} \mathrm{C}\right)$ stand for the moral-action-form " $x$ 's body temperature is made less than 20 degrees above zero centigrade." And let $\left(\mathrm{t}>+60^{\circ} \mathrm{C}\right)$ stand for the moral-action-form " $x$ 's body temperature is made more than 60 degrees above zero centigrade." If the concrete circumstances of the situation are quite determined and the variables $x$ and $\Sigma$ are fixed, then the moral-action-forms $\left(\mathrm{t}<+20^{\circ} \mathrm{C}\right)$ and $\left(\mathrm{t}>+60^{\circ} \mathrm{C}\right)$ become moral actions which are either good or bad from the viewpoint of the evaluator $\Sigma$. In the two-valued algebra of formal ethics of moral rigor, for any $x$ and $\Sigma$, it is true that $\left(\left(\mathrm{t}<+20^{\circ} \mathrm{C}\right)=+=\left(\mathrm{t}>+60^{\circ} \mathrm{C}\right)\right)$. This formal-axiological equation deals with empirically fixed accidental moral-legal values exclusively: It has no formal-logic entailment relations to corresponding statements of facts. According to the above formulation of the general separation principle under exemplification, $\beta\left(\mathrm{t}<+20^{\circ} \mathrm{C}\right)$ stands for the fact-fixing-proposition " $x$ 's body temperature is made less than 20 degrees above zero centigrade", and $\beta\left(\mathrm{t}>+60^{\circ} \mathrm{C}\right)$ stands for the fact-fixing-proposition " $x$ 's body temperature is made more than 60 degrees above zero centigrade." Being propositions about facts, $\beta\left(\mathrm{t}<+20^{\circ} \mathrm{C}\right)$ and $\beta\left(\mathrm{t}>+60^{\circ} \mathrm{C}\right)$ are either true or false ones. Hence, it is quite natural to connect these two fact-fixing-propositions by the binary logic operation “ $\leftrightarrow$ ” (logic equivalence). The compound proposition $\left(\beta\left(\mathrm{t}<+20^{\circ} \mathrm{C}\right) \leftrightarrow \beta\left(\mathrm{t}>+60^{\circ} \mathrm{C}\right)\right)$ is nothing but logic connection of facts: It has nothing to do with values. According to the above separation rule, if one implements the following "logic inference," the one commits the blunder, as there is no logic consequence relation between the "premise" and the "corollary."

$$
\frac{\left(\left(\mathrm{t}<+20^{\circ} \mathrm{C}\right)=+=\left(\mathrm{t}>+60^{\circ} \mathrm{C}\right)\right)}{\left(\beta\left(\mathrm{t}<+20^{\circ} \mathrm{C}\right) \leftrightarrow \beta\left(\mathrm{t}>+60^{\circ} \mathrm{C}\right)\right)}
$$

Here committing the jump from the alleged premise to the alleged corollary is strictly forbidden by the rule A. Violating this rule can result in a logic catastrophe: deriving evidently false purely factual "conclusion" from obviously true (from the empirical viewpoint) purely evaluative "premise." Also the rule strictly prohibits the converse jump from the evident falsity of $\left(\beta\left(\mathrm{t}<+20^{\circ} \mathrm{C}\right) \leftrightarrow \beta\left(\mathrm{t}>+60^{\circ} \mathrm{C}\right)\right)$ to falsity of $\left(\left(\mathrm{t}<+20^{\circ} \mathrm{C}\right)=+=\left(\mathrm{t}>+60^{\circ} \mathrm{C}\right)\right)$ by "modus tollens" as there is no logic entailment relation between the two substantially different formal equivalences. Thus, the abstract separation rule is exemplified. However, this quite impressive exemplification is far away from the paper theme. Therefore, below such an instantiation is given which is just about the above-discussed Trinity-triangle inconsistency-problem. Let the above true formal-axiological equation (4) is used as allegedly a premise of the following invalid argument (forbidden by the rule A).

$$
\begin{aligned}
& F G x=+=S G x: \text { The Father is The Son. } \\
& \hline(\beta(F G x) \leftrightarrow \beta(S G x)): \text { The Father is The Son. }
\end{aligned}
$$

Here at the level of natural language, the defectiveness of the argument is imperceptible as it is quite masked by the above-mentioned dangerous ambiguity of the word-homonym "is." In the "premise," the word "is" stands for the axiological equivalence "=+=" but in the "corollary," the word "is" stands for the logical equivalence " $\leftrightarrow$ ". The "premise" $F G x=+=S G x$ is true but the "corollary" $(\beta(F G x) \leftrightarrow \beta(S G x))$ is false as, in fact, the Father is not the Son (see the above triangle). But using the "modus tollens" here for constructing the logic inconsistency under discussion is irrelevant as there is no logical consequence relation between the "premise" and the "corollary." Thus, the abstract rule under consideration is instantiated in relation to the 
concrete theme of this paper.

Also the famous "is-ought" problem is quite a representative particular case of a great number of substantially different situations to be regulated effectively by the above-formulated general separation rule. Originally just the specific "is—ought" problem raised by D. Hume was called "Guillotine of Hume." Thus, initially the name "Guillotine of Hume" meant just that very important particular philosophical-logic problem (of deriving "is" from "ought") but not a solution of it. However, in principle, this meaning (understood as statistical norm of usage) of the name "Guillotine of Hume" can be significantly changed during the flow of time and, in particular, significantly generalized. In fact, just this possibility has been realized in history of philosophy. Today statistical norm of usage of the name "Guillotine of Hume" in philosophical talks and writings differs much from the initial one. Generally speaking in history of science such shifting meanings of words happens systematically (it is a statistical norm of science language development) and in principle this shifting of meanings makes no problem unless the meaning-change is not recognized manifestly or not taken into an account systematically. The following part of this paper is devoted just to manifest recognizing, precise indicating, and emphasizing the significant change of meaning of the name "Guillotine of Hume."

\section{A Historic Remark Concerning the So-called "Guillotine of Hume"}

Evidently, that abstract formal rule of separating facts and empirical values which is precisely formulated above in general is very far away from that small bit of text of D. Hume's "Treatise of Human Nature" which was named "Guillotine of Hume" originally. I think that hereabout it is quite relevant to cite that small piece of text to be found in the "Treatise" (Book III. Of Morals. Part I. "Of Virtue and Vice in General." Section I. "Moral Distinction Not-Derived from Reason"):

\footnotetext{
I cannot forbear adding to these reasonings an observation, which may, perhaps, be found of some importance. In every system of morality, which I have hitherto met with, I have always remarked, that the author proceeds for some time in the ordinary way of reasoning, and establishes the being of a God, or makes observations concerning human affairs; when all of a sudden I am surprised to find, that instead of the usual copulations of propositions, is, and is not, I meet with no proposition that is not connected with an ought, or an ought not. This change is imperceptible; but is however, of the last consequence. For as this ought, or ought not, expresses some new relation or affirmation, it is necessary that it should be observed and explained; and at the same time that a reason should be given, for what seems altogether inconceivable, how this new relation can be a deduction from others, which are entirely different from it. But as authors do not commonly use this precaution, I shall presume to recommend it to the readers; and am persuaded, that this small attention would subvert all the vulgar systems of morality, and let us see, that the distinction of vice and virtue is not founded merely on the relations of objects, nor is perceived by reason. (Hume 1874, 245-6)
}

Pondering over the cited bit of the "Treatise," one can notice that D. Hume himself did not answer the question: he only raised it; for the first time in the world philosophy history he recognized and manifestly formulated the very important problem worthy of investigation. However, his successors (opponents or proponents) ascribed to Hume the perfectly definite, namely, negative answer to the nontrivial philosophical logic question he had originally formulated and suggested to think about in the above-cited bit of the text. Factually, according to the statistics, nowadays usually the name "Hume's Guillotine" stands for the negative answer ascribed to Hume by his successors. Although from the proper historical point of view, such contemporary linguistic habit of using the name "Hume's Guillotine" is not well-grounded, in the given paper "Hume's Guillotine" means just the negative answer ascribed to Hume by his successors. Thus, in the present paper, the meaning of the term "Guillotine of Hume" is quite a conventional one. 
Nevertheless this conventional-ness is not a problem for the present paper devoted mainly not to concrete history of philosophy but to abstract philosophical logic theory. From the purely theoretical point of view, it is quite sufficient that the conventional meaning of the term "Guillotine of Hume" is defined. Evidently, the definition of it is not absolutely precise as Hume himself wrote only about the famous "is—ought" problem, i.e., only about a modest particular case (the deontic or normative one) of the above-formulated significantly generalized formal rule (U\&Q). Another modest particular case (the axiological or evaluative one) of the above significantly generalized formal rule (U\&Q) is the famous "is-good" problem. Also there are many other particular cases (theoretically interesting and practically important ones) of the above-submitted general rule (U\&Q).

Consequently, the above-formulated abstract separation principle sometimes conventionally called in my publications "Guillotine of Hume," is a fundamental generalization of the negative answer to Hume's question. This fundamental generalization is formulated by means of artificial language of two-valued algebraic system of formal ethics of moral rigor (Lobovikov 2007; 2014a; 2014b).

\section{Binary Formal-Axiological Operations in Two-Valued Algebra of Formal Ethics of Moral Rigor and Precise Defining the Notion "Formal-Axiological Entailment (among Actions)" in That Algebra}

Hitherto in this paper only unary moral operations of algebra of formal ethics were introduced and precisely defined (by the above Tables 1 and 2). However, being a fundamental generalization of two-valued algebra of classical logic, the two-valued algebra of formal ethics of moral rigor under consideration in this paper contains all the 16 binary operations of the logic algebra as particular cases of 16 binary operations of the morality algebra respectively. Below an exemplification of this statement is submitted. (Concentrating on the main theme of this paper, I am to abstain from exemplifying all the 16 operations: Here only some of them are to be introduced and defined precisely.)

The glossary for the below-submitted moral-value-table 3: The symbol $K_{2} x y$ stands for the binary formal-axiological operation (evaluation-function) "uniting, conjoining, combining moral-legal actions (or persons) $x$ and $y$ in a conduct (or person) as a whole." $C_{2} x y$ stands for the binary formal-axiological operation (evaluation-function) "action (or person) $y$ proceeds from action (or person) $x$." $A_{2} x y$ stands for " $y$ 's offensive, attack, assault on (what, whom) $x$." (It is worth noting that $C_{2} x y$ and $A_{2} x y$ are mathematically dual to each other.) The formal-axiological (evaluation-functional) sense of the mentioned binary operations of algebra of formal ethics of moral rigor is defined by the following Table 3.

Table 3

Binary Operations

\begin{tabular}{lllll}
\hline$x$ & $y$ & $K_{2} x y$ & $C_{2} x y$ & $A_{2} x y$ \\
\hline $\mathrm{g}$ & $\mathrm{g}$ & $\mathrm{g}$ & $\mathrm{g}$ & $\mathrm{b}$ \\
$\mathrm{g}$ & $\mathrm{b}$ & $\mathrm{b}$ & $\mathrm{b}$ & $\mathrm{b}$ \\
$\mathrm{b}$ & $\mathrm{g}$ & $\mathrm{b}$ & $\mathrm{g}$ & $\mathrm{g}$ \\
$\mathrm{b}$ & $\mathrm{b}$ & $\mathrm{b}$ & $\mathrm{g}$ & $\mathrm{b}$ \\
\hline
\end{tabular}

Now within the two-valued algebra of formal axiology of morality, let us define precisely a formal-ethical entailment (consequence) relation between moral-action-forms deprived of their specific contents. 
Definition 4 (of formal-axiological consequence relation): in two-valued algebra of formal ethics, a moral-evaluation-function $\Omega$ formally-ethically follows (proceeds) from a moral-evaluation-function $\Psi$ (or, in other words, $\Psi$ formally-axiologically entails $\Omega$ ), if and only if the moral-evaluation-function $C_{2} \Psi \Omega$ acquires the moral-value $g$ (good) under any possible combination of moral-values of its variables. In the expression $C_{2} \Psi \Omega$, the symbol $\mathrm{C}_{2}$ is used in that specific moral-value-functional sense which is precisely defined above by the Table 3 (column 3).

Hence, interconnections between the formal-logical-consequence relation (among thought-and-speech acts) and the formal-ethical-consequence relation (formal-axiological procession one among moral-acts-in-general) can be represented by the following Figure 5 .

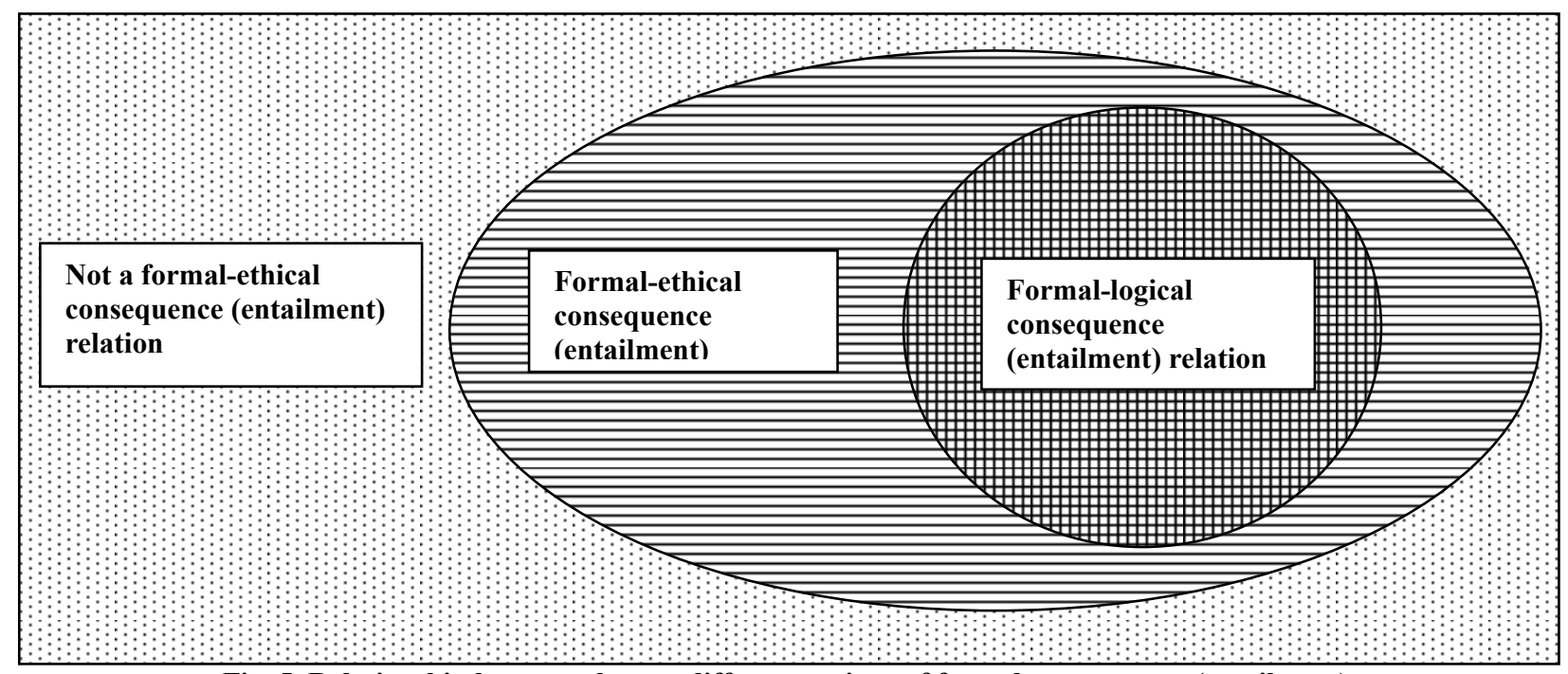

Fig. 5. Relationship between the two different notions of formal consequence (entailment).

According to this picture (and to the above definition 4), the formal-logical consequence (entailment) relation among thought-and-speech-acts is a specific particular case of the formal-ethical (formal-axiological) consequence (entailment) relation among acts in general. I believe that the fact of significant difference between these two kinds of formal entailment relations gives a possibility effectively to destroy the logic-linguistic illusion of formal-logic inconsistency of the Holy Trinity. The illusion in question is quite a natural psychological effect caused by the ambiguity of natural language to be neutralized by systematical using the artificial language of mathematical ethics.

The Holy Trinity doctrine contains a difficult problem for those rationalist-minded Christians who attempt harmonically to unite logic with their religion. Obviously for such Christians, there are two strategies of solving the problem. The first strategy is based on the classical logic and targeted at demonstrating that there is not a logic inconsistency in the Trinity doctrine but only an illusion of the one caused by the ambiguity of natural language. The present paper represents an attempt to realize just this strategy.

However, it is worth recognizing that there is also another option of solving the problem: The second strategy of coping with the difficulty combines recognizing the fact of logic inconsistency and not-recognizing the relevance of classical logic. Some system of paraconsistent logic (Béziau 1999; Béziau, Costa 2015; Costa 1974; Costa, Krause, Bueno 2007) can be used instead of the classical one for neutralizing the danger of logic inconsistency, if the fact of logic contradiction is recognized. 
I believe that for the sake of establishing harmony between logic and religion it is worth taking seriously and investigating systematically both strategies.

\section{Notes}

1. This concrete picture is created by me although the general idea of the Trinity triangle is very old one and one can find other options of picturing it created by other authors.

2. Łukasiewicz was not unique in treating logic as a particular case of ethics (understood as philosophy of morals necessarily dealing with either evaluative or normative statements). In history of philosophy, many thinkers had the same attitude to logic. In our days, the idea of "logic as a moral science" is developed by famous Australian logician Hartley Slater (2015a; 2015b). Also treating logic as a brunch of ethics is presented in LaVine's papers (2015).

\section{Works Cited}

Aquinas, Thomas. St. "The Summa Theologica. V. I.” Ed. Adler Mortimer. Great Books of the Western World. V. 17. Aquinas: I. Chicago; Auckland; London; Madrid: Encyclopaedia Britannica, Inc., 1994a.

---. "The Summa Theologica. V. II." Ed. Adler Mortimer. Great Books of the Western World. V. 18. Aquinas: II. Chicago; Auckland; London; Madrid: Encyclopaedia Britannica, Inc., 1994b.

Anderson, Anthony. "Some Emendations on Godel's Ontological Proof." Faith and Philosophy 7 (1990): 291-303.

Augustine, St. The Trinity. Washington: The Catholic University of America Press, 1963.

---. "The Confessions. The City of God. On Christian Doctrine." Ed. Adler Mortimer. Great Books of the Western World. V. 16. Augustine. Chicago; Auckland; London; Madrid: Encyclopaedia Britannica, Inc., 1994.

Bertato, Fabio. "The Logic of the Trinity and the Filioque Question in Thomas Aquinas." Ed. Ricardo Sousa Silvestre and Jean-Yves Beziau. Handbook of the 1st World Congress on Logic and Religion (João Pessoa, April 1-5, 2015, Brazil). João Pessoa: Federal University of Campina Grande; Federal University of Paraiba; Federal University of Rio de Janeiro; Brazilian Academy of Philosophy, 2015. 76-77.

Bertato, Fabio and Toniolo João. "On the Logical Consistency of Trinity and the Triad Memory, Understanding and Will in the Augustinian System.” Ed. Ricardo Sousa Silvestre and Jean-Yves Beziau. Handbook of the 1st World Congress on Logic and Religion (João Pessoa, April 1-5, 2015, Brazil). João Pessoa: Federal University of Campina Grande; Federal University of Paraiba; Federal University of Rio de Janeiro; Brazilian Academy of Philosophy, 2015. 106-7.

Bjørdal, Frode. "All Properties Are Divine or God Exists: An Ontological Argument with Apathiatheistic and Confidentialistic Remarks." Ed. Ricardo Sousa Silvestre and Jean-Yves Beziau. Handbook of the 1st World Congress on Logic and Religion (João Pessoa, April 1-5, 2015, Brazil). João Pessoa: Federal University of Campina Grande; Federal University of Paraiba; Federal University of Rio de Janeiro; Brazilian Academy of Philosophy, 2015. 86-88.

Béziau, Jean-Yves. "What Is Paraconsistent Logic?" Frontiers of Praconsistent Logic. Baldock: Research Studies Press, 1999. 95-112.

Béziau, Jean-Yves and Newton da Costa. "Is God Paraconsistent?” Ed. Ricardo Sousa Silvestre and Jean-Yves Beziau. Handbook of the 1st World Congress on Logic and Religion (João Pessoa, April 1-5, 2015, Brazil). Joao Pessoa: Federal University of Campina Grande; Federal University of Paraiba; Federal University of Rio de Janeiro; Brazilian Academy of Philosophy, 2015. 25.

Costa, Newton da. "On the Theory of Inconsistent Formal Systems." Notre Dame Journal of Formal Logic 15 (1974): $497-510$.

Costa, Newton da, Décio Krause, and Otávio Bueno. "Paraconsistent Logics and Paraconsistency." Ed. Dale Jacquette. Philosophy of Logic (Handbook of the Philosophy of Science). Amsterdam: North-Holland Publishing Co., 2007. 791-912.

Fitting, Melvin Chris. Types, Tableaus, and Gödel's God. Dordrecht: Kluwer, 2002.

Fuhrmann, André. "Existence and Necessity. Kurt Gödel's Axiomatic Theology." Ed. Wolfgang Spohn et al. Logic in the Philosophy. Heidelberg (Synchron): Synchron Publishers, 2005. 349-74.

Fuhrmann, André. “Gödel's Ontological Argument in the Public Eye.” Ed. Srécko Kovač, Kordula Šwietorzecka. Formal Methods and Science in Philosophy (International Conference at Inter-University Center, Dubrovnic, Croatia, March 26-28, 2015). Zagreb, Croatia: Institute of Philosophy, 2015. 4. 
Gödel, Kurt. "Ontological Proof." Collected Works. Volume III: Unpublished Essays \& Lectures. New York: Oxford University Press, 1995. 403-4.

Hume, David. "A Treatise of Human Nature Being an Attempt to Introduce the Experimental Method of Reasoning into Moral Subjects." Ed. Thomas Hill Green and Thomas Hodge Grose. The Philosophical Works of David Hume in Four Volumes. Vol. II. London: Longmans, Green, and Co., 1874. 1-374.

Janowitz, Naomi. "Theories of Divine Names in Origen and Pseudo-Dionysius." History of Religions 30 (1991): 359-72.

LaVin, Matt. "The Future of Logic (and Ethics).” Ed. Jean-Yves Béziau, Şafak Ural, Arthur Buchbaum, Iskender Taşdelen, and Vedat Kamer. UNILOG 2015: Handbook of the 5th World Congress and School on Universal Logic (June 20-30, 2015, Istanbul, Turkey). Istanbul: University Press, 2015. 384.

Lobovikov, Vladimir. Modal Logic of Evaluations and Norms from the Viewpoint of Content Ethics and Jurisprudence. Krasnoyarsk: The University Press, 1984.

---. Mathematical Jurisprudence and Mathematical Ethics. Yekaterinburg: The Urals State University Press; Ural State Law Academy Press; Liberal Arts University Press, 1999.

---. “Aristotelian and Juridical Modalities: A New Theory of Their Unity (A Two-Valued Algebra of Formal Natural-Law Philosophy of Modalities as Moral-Legal Evaluation-Functions Determined by Two Variables-A Complement to G. H. Wright's Deontic Logic Interpretation of G. W. Leibniz's Idea about the Unity of the Two Kinds of Modalities)." Brazilian Legal Theory Review - RFDCL (Revista da Faculdade de Direito de Conselheiro Lafaiete) 3 (2007): 181-7.

---. "Mathematical Logic as a Particular Case of Mathematical Ethics (Algebra of Formal Ethics as a Generalization of Algebra of Formal Logic)." Ed. Costas Drossos, Pavlos Peppas, Constantine Tsinakis. Proceedings of the 7th Panhellenic Logic Symposium (PLS7) at Patras University, Greece, July 15-19, 2009. Patras, Greece: Patras University Press, 2009a. 109-11.

---. "Mathematical Simulating Formal Axiological Semantics of Natural Languages (A Fundamental Generalization of Mathematical Philosophy: From Truth-Values to Axiological Ones)." Philosophy, Mathematics, Linguistics: Aspects of Interconnection: Proceedings of the International Scientific Conference (November 20-22, 2009, Sankt-Petersburg, L. Euler International Mathematical Institute). St.-Petersburg: VVM, 2009b. 128-32.

---. "Algebra of the Natural Law-A Mathematical Simulation of the Natural Law Type of Legal Reasoning: A Basis for Computer-Aided Law-Making and Law Education." Review of Philosophy of Law and Social Philosophy (ARSP)—the International Journal of the IVR—-the International Association for Philosophy of Law and Social Philosophy 122 (2010a): 105-14.

---. "Between Writing and Picturing: The Square of Opposition in Formal Logic and Formal Axiology of Alethic and Deontic Modalities.” Ed. Elisabeth Nemeth, Richard Heinrich, and Wolfram Pichler. Image and Imaging in Philosophy, Science, and the Arts. Papers of the 33rd International Wittgenstein Symposium (August 8-14, 2010, Kirchberg am Wechsel, Lower Austria). Contributions of the Austrian Ludwig Wittgenstein Society: Volume XVIII. Kirchberg am Wechsel: Austrian Ludwig Wittgenstein Society, 2010b. 183-5.

---. 'Discrete Mathematical Representing G. W. Leibniz' Philosophy of Law, Morals and Theology by Means of Two-Valued Algebra of the Natural Law (Studying Moral-legal Evaluation-Functions Determined by Two Variables in Algebra of Formal Axiology)." Ed. Herbet Breger, Jürgen Herbst, and Sven Erdner. XI International Leibniz-Congress "Nature and Subject" under the Auspices of Federal President (Hannover, 26 September until 1 October 2011). Volume 2. Berlin: Akademie Verlag; Bahlsen GmbH \& Co. KG, 2011. 611-5.

---. "Algebra of Morality and Formal Ethics." Ed. Bronk. Katarzyna. Looking Back to See the Future: Reflections on Sins and Virtues. Oxford: ID Press, 2014a. 17-41.

---. "Squares and Hexagons of Formal-Ethical Opposition in Two-Valued Algebra of Formal Ethics. An Algebraic System of Moral-Evaluation-Functions: "Being", "Knowing", "Faith", "Love", et al." Aporia-International Review of Philosophical Investigations/Santiago de Chile 8 (2014b): 4-22.

---. "The Trinity Triangle and the Homonymy of the Word "Is" in Natural Language: Eliminating the Illusion of Logical Inconsistency by Precise Formulating the Principle of Separation of Facts and Values in Algebra of Formal Ethics." Ed. Ricardo Sousa Silvestre and Jean-Yves Beziau. Handbook of the 1st World Congress on Logic and Religion (João Pessoa, April 1-5, 2015, Brazil). João Pessoa: Federal University of Campina Grande; Federal University of Paraiba; Federal University of Rio de Janeiro; Brazilian Academy of Philosophy, 2015. 176-7.

Oppy, Graham. Ontological Arguments and Belief in God. New York: Cambridge University Press, 1995.

Plantinga, Alvin. The Ontological Argument from St. Anselm to Contemporary Philosophers. Garden City: Doubleday, 1965.

Pseudo-Dionysius. The Divine Names and Mystical Theology. Trans. John Jones. Milwaukee: Marquette University Press, 1980. 
Rocha, Renato. "Trinity and Mereology." Ed. Ricardo Sousa Silvestre and Jean-Yves Beziau. Handbook of the 1st World Congress on Logic and Religion (João Pessoa, April 1-5, 2015, Brazil). João Pessoa: Federal University of Campina Grande; Federal University of Paraiba; Federal University of Rio de Janeiro; Brazilian Academy of Philosophy, 2015. 148-9.

Schang, Fabian. "Silence Has No Logical Value. Making Sense of Nonsense, behind and beyond the Tractatus 7." Handbook of the World Congress on the Square of Opposition IV (May 5-9, 2014, Pontifical Lateran University, Vatican). Poznan-Poland: Publishing House "Kontext", 2014. 129-30.

Slater, Hartley. "Logic Is a Moral Science.” Philosophy (2015a): Available on CJO2015. doi:10.1017/S003181911500025X.

---. "The Future of Logic.” Ed. Jean-Yves Béziau, Şafak Ural, Arthur Buchsbaum, Iskender Taşdelen, and Vedat Kamer. UNILOG 2015: Handbook of the 5th World Congress and School on Universal Logic (June 20-30, 2015, Istanbul, Turkey). Istanbul: University Press, 2015b. 386.

Sobel, Jordan Howard. “Godel's Ontological Proof.” Ed. Judith Jarvis Thomson. On Being and Saying. Essays for Richard Cartwright. Cambridge: MIT Press, 1987. 241-61.

Steinhart, Eric. "A Mathematical Model of Divine Infinity.” Theology and Science 7.3 (2009): 261-74.

Trepczyński, Marcin. "The Local Logic in Christian Theology." Ed. Ricardo Sousa Silvestre and Jean-Yves Beziau. Handbook of the 1st World Congress on Logic and Religion (João Pessoa, April 1-5, 2015, Brazil). Joao Pessoa: Federal University of Campina Grande; Federal University of Paraiba; Federal University of Rio de Janeiro; Brazilian Academy of Philosophy, 2015. 122-3.

Voss, Sarah. Mathematical Theology. <http://www.uuworld.org/2003/03/interpretation.html>.

Weingartner, Paul. "The Problem of the Definition or Description of God in Gödel's and Other Ontological Proofs." Ed. Srécko Kovač and Kordula Šwietorzecka. Formal Methods and Science in Philosophy (International Conference at Inter-University Center, Dubrovnic, Croatia, March 26-28, 2015). Zagreb: Institute of Philosophy, 2015. 3.

Woleński, Jan. "Lvov-Warsaw School.” Ed. Edward Zalta. The Stanford Encyclopedia of Philosophy (Spring 2014 Edition). $<$ http://plato.stanford.edu/archives/spr2014/entries/lvov-warsaw/>. 